\title{
Something Old, Something New, Something Blue
}

Leaders in all fields remain on top through innovation and improvement, and The Journal of Clinical Investigation (JCI) is no exception. In 1987, the JCI ranked among the top $1 \%$ of 4,300 journals in both total citations and overall impact $(1,2)$. The current editors have made it their highest priority not only to maintain the high standards of the JCI, but also to build upon its strong tradition and identify areas for constructive change.

In his introductory editorial to the first issue of the $\mathrm{JCI}$ in 1924, Dr. Alfred Cohn emphasized that the then-emerging discipline of clinical investigation must be cognizant of and profit from advancements in the basic sciences, while at the same time focusing on its own objectives of better understanding human biology and curing disease (3). Spectacular recent advances in cellular and molecular biology present new opportunities and challenges for today's clinical investigators and have broadened the traditional view of what clinical investigation entails. Increasingly, important advances in medicine represent the work of physicians properly trained in and conversant with the biological sciences.

The fast pace of these advances also brings new challenges to the JCI. The current editors believe that JCI must provide its readers with the most up-to-date information available and should focus on areas in which advances in basic research provide new information about or perspective on disease mechanisms. We are currently able to publish only a minority of the nearly 2,000 articles submitted each year, and we have therefore assigned the highest priority to forward-looking articles likely to be of interest to a general audience. To enhance the value of the JCI to readers and authors, the editors have also made the following changes in style and operation.

First, we are planning to publish more "Perspectives" articles. These minireviews focus on rapidly developing areas of importance to human biology or disease that may not have received much attention elsewhere. We are both receptive to suggestions for Perspectives topics and pleased to review unsolicited manuscripts that conform to the style and purpose of articles in this series.

Second, we have formally solicited a select number of original articles from investigators presenting outstanding abstracts at the annual meeting of the American Society for Clinical Investigation (ASCI) and its sister societies. Solicitation is not accompanied by an advance commitment to publish, but such articles do undergo an expedited review. We anticipate that similar invitations will be extended to investigators presenting work at other scientific fora as well.

Third, changes have been made in the review process. A major strength of the $\mathrm{JCI}$ is its strong tradition of the rigorous and thorough review of submitted articles $(4,5)$. This will be maintained. In addition to the local core group of associate editors, five consulting editors at different institutions now share decision-making responsibilities on submitted articles. Their scientific interests and backgrounds complement those

J. Clin. Invest.

(c) The American Society for Clinical Investigation, Inc.

0021-9738/90/01/0001/01 $\$ 2.00$

Volume 85, January 1990, 1 of the associate editors and broaden the expertise that can be brought to bear on manuscripts in specialized areas.

The editors also place a high priority on timeliness. Electronic communication and tracking are in place and have improved response time. "Rapid Publications" represent an increasingly important mechanism for reporting advances in fast-moving, competitive areas. Editorial decisions are typically made in three to four weeks, and accepted articles are published within two to three months.

Fourth, the JCI will publish two tables of contents, one of which will be categorical in nature. These categories do not conform to traditional clinical specialty or subspecialty areas. Rather, the categories are broad and emphasize processes relevant to many clinical disciplines, thus building upon the strengths of the JCI as a general journal focusing on human biology and disease.

Fifth, we have changed the appearance of the JCI to make it more attractive and informative. The new cover lists the categories that will be used to classify articles and includes a figure. Cover figures will be selected both for their artistic and scientific merit. While we are particularly interested in figures that pertain to Perspectives articles, appropriate figures accompanying all articles are potential candidates, and we urge submitting authors to call to our attention figures that they wish to be considered.

Finally, we call your attention to several changes in the "Instructions to Authors." A statement signed by all authors regarding prior publication and approval of submission is now requested for all manuscripts. Submitted articles are to be accompanied by several keywords to facilitate their retrieval by electronic search. Because of continually escalating mail costs, only original manuscripts and figures will be returned to authors. Please also note the new guidelines regarding submission of sequence data, manuscript length, and delayed resubmission of manuscripts.

In introducing these changes, the editors wish to thank several individuals for their strong support and counsel. Those include Drs. Robert J. Lefkowitz, C. Ronald Kahn, and Stuart H. Orkin, past and current presidents of the ASCI, and Dr. Ralph Snyderman, Chairman of the JCI Advisory Committee. We anticipate these changes will enhance the value and attractiveness of the JCI to clinical investigators interested in human biology and disease, and we continue to welcome their constructive comments.

Bruce F. Scharschmidt, M.D.

Editor

\section{References}

1. SCI Journal Citation Reports. 1988. Institute for Scientific Information. Philadelphia.

2. Garfield, E. 1987. Fifty classics from The Journal of Clinical Investigation: Over 60 years of Nobel-class research. Current Contents. 8:3-8.

3. Cohn, A. E. 1924. Purposes in medical research. An introduction to the Journal of Clinical Investigation. J. Clin. Invest. 1:1-11.

4. Wilson, J. D. 1978. Peer review and publication. J. Clin. Invest. 61:1697-1701.

5. Kelley, W. N. 1984. Clinical investigation and the clinical investigator. The past, present, and future. J. Clin. Invest. 74:1117-1122. 